\title{
Interrogating borders: a transnational approach to refugee research in Vancouver
}

\author{
JENNIFER HYNDMAN, \\ Department of Ceography, Simon Fraser University, 8888 University Drive, Burnaby, BC, Canada V5E 156 (e-mail: hyndman(osfu.ca)
}

MARGARET WALTON-ROBERTS

Department of Geography, University of British Columbia, 1984 West Mall, Vancouver, BC, Canada V6T 122 (e-mail: walton@unixg.ubc.ca)

Immigration is predicated on the centrality of the nation-state. The authors argue that analyzing settlement patterns and successful integration within a strictly national context is insufficient to understand the political, social, and economic relations which shape the lives of refugee immigrants in Canada. To support this claim, a less state-centric theoretical framework of transnational migration is outlined. The paper examines methods emerging from transnational migration, focussing in particular on research with Burmese refugees who have settled in the Greater Vancouver Area. Based on 50 personal interviews conducted with refugee newcomers from Burma who are now settled in the Lower Mainland, the authors use the case study as a basis to raise methodological and theoretical questions about immigration research. We argue that the very politics of doing research with this group of refugees and other immigrant groups are shaped by the relations of power experienced before arriving in Canada.

keywords: immigration, transnationalism, methodology, refugees
Les auteures soutiennent que l'analyse des schémas d'établissement et d'intégration réussie dans un contexte strictement national s'avère insuffisante pour comprendre les relations politiques, sociales et économiques qui définissent l'existence des réfugiés immigrants au moment de larrivée. Dans le but d'appuyer cette proposition, nous définissons un schéma théorique moins axé sur létat, c'est-à-dire le transnationalisme. La recherche examine ces facteurs en relation avec les expériences des 'immigrants nontraditionnels' au Canada, en particulier les réfugiés Burmans installés dans la région de Vancouver. Basés sur 50 entrevues personnelles menées avec des réfugiés nouvellement arrivés du Burma et qui sont maintenant installés dans le 'Lower Mainland', les auteures utilisent l'étude de cas comme une base permettant de soulever des questions de méthodologie pour la recherche en immigration. Nous avançons que les implications politiques de la recherche avec ce groupe de réfugiés et d'autres groupes d'immigrants dépendent des relations de pouvoir vécues avant l'arrivée au Canada.

mots-clés: immigration, transnationalisme, méthodologie, réfugiés 
Immigration begins with the premise that a newcomer's primary attachments to place - whether they be social, political, or economic - shift from one's former country of emigration to one's new country of immigration. In this paper, we challenge this binary assumption at a theoretical level, by demonstrating the state-centric tendencies of immigration discourse, and at an empirical level, by illustrating the multiple and messier relations of migrants to states based on the refugee experience of Burmese migrants who have settled in Canada. We contend that conventional immigration approaches, including those of demography, population geography, and economics, largely ignore conditions in and relations with the so-called source country, rendering them unable to capture the social and spatial spectrum of experience associated with displacement. A transnational approach to migration generates a more dynamic and comprehensive analysis, one which highlights a potentially transformative politics based on the movement of people, money, and information both within and beyond Canadian borders. Such an approach, we further argue, depends on close collaboration with the migrants whose livelihoods are being considered. Transnational migration research - especially that concerning refugees forced from their countries - requires a methodological approach that is not only communitybased, but one in which the migrants participating shape the research objectives and render the research relevant to their own concerns, local and transnational.

The research on which this paper is based began as an inquiry into the relationship between language ability and job success among 'non-traditional immigrant groups' in Canada. The project was partly funded by the Federal Department of Canadian Immigration and Citizenship (CIC), which had input into the research questions through the Metropolis Project, its national initiative on urban immigration research. The research is complete, and the empirical results related to official language ability and employment achievement have been published on-line and in text (see Hyndman and Walton-Roberts 1999). The project from its inception embodied a critical reappraisal of this prescribed research agenda, one which insisted on shifting the focus of research from exclusively resettlement success, as measured by language ability and jobs, to terms which also accommodat- ed the agenda and interests of the newcomers themselves. Accountability to the subjects of the research, we reasoned, was as important as accountability to funders. To this end, the paper deals with certain theoretical aspects of the larger project of transnationalism.

This paper focuses on newcomers to Vancouver from Burma, a lesser known group whose small size and relatively recent arrival has averted the attention of settlement agencies, immigration officials, and researchers for the most part. Refugees to Canada from Burma are arguably a 'non-traditional' immigrant group. 'Non-traditional' is a term used but not explicitly defined by $\mathrm{CIC}$. People born in places like Burma, also known as Myanmar, represent a non-traditional immigrant group in two ways. First, the group is relatively new to Canada; it is one which has not been counted among major immigrant-sending countries to Canada and Burmese arrivals did not begin in earnest until the 1990s. Second, Burmese refugees come to Canada from a country adversely affected by the widespread violation of human rights and documented state-sponsored violence. That is to say, most enter disproportionately as Convention Refugees and refugee claimants. They are literally forced to choose Canada or some other resettlement country. We contend that status as refugees or refugee claimants upon arrival distinguishes Burmese newcomers from other immigrant classes in important ways. Not only are they smaller and newer than most other immigrant groups, their reasons for leaving and conditions of departure are very different. Their intimate connections to people in Thai refugee camps, from which they came, and to members of the Burmese diaspora in other locations are distinctive.

We begin by examining transnational approaches to migration which challenge the conventions of immigration discourse. How, if at all, can transnationalism elucidate the relationships, identities, and experiences of 'immigrants' better than existing immigration conventions? The paper then moves to the antecedents of Burmese immigration to Canada, including a sketch of the scale and scope of Burmese displacement to neighbouring Thailand. We outline the movement of Burmese to Canada, and the transnational implications of their migration. Finally, we address the issue of methodology by scrutinizing our own community collaboration with the Burmese Democratic Organization, 
and reflecting upon the shortcomings as well as the political promise of this approach. In a critical attempt to ascertain the impact of methodology and theoretical debates on research relating to transnational migration, we evaluate the modes of knowledge production employed, and postulate improvements to such collaborations for future research.

\section{Transnationalism: Questioning Immigration Discourse}

Transnationalism is, then, not simply a theoretical perspective, but a nexus of social and material relationships which blur the centrality of borders. The discourse of transnationalism emerged from a synthesis of two dominant modes of thought in the 1980s: postmodernism, which emphasized more fragmented relations between knowledge and power enabled, in part, by new technology; and Marxist critiques which paid attention to the material transformations associated with increasingly global capitalism (Shami 1996). In outlining the various proponents and critics of transnationalism, we link our findings of social and political connections across space with a theoretical literature which has not conventionally been associated with Canadian immigration studies. As a more comprehensive theoretical framework, both spatially and culturally speaking, transnationalism has seen increasingly widespread use within anthropology, (Gupta and Ferguson 1992; Appadurai 1996), cultural studies, (Hall 1991), sociology (Goldring 1996), and more recently within geography, (Mountz and Wright 1996; Mitchell 1997; Hyndman 1997; Nolin Hanlon and Kobayashi 1998). Our interest in transnational connections emerges from recognition that links with friends, relatives, and political allies beyond Canadian borders shape the lives of Burmese refugees who have become landed immigrants in this country. While Burmese refugees living on the West Coast may not travel back and forth to Thailand and Burma on a regular basis, the personal, political, and economic exchanges among Burmese in these locations are significant. Policy-oriented immigration language renders such networks invisible, or at best, extraneous. Their implications for refugee settlement are potentially significant, yet the political, economic, and socio-cultural characteristics of such relations remain largely under erasure.
Transnational approaches to migration offer a corrective to this erasure by focusing specifically on issues of state-centrism, identity, and space.

\section{State-centrism}

Rarely in immigration circles dominated by demographers and economists are the limits of migration language discussed, nor is the assumption that the receiving nation is the primary and dominant venue of migration questioned. The possibility and reality that newcomers to Canada are participants in extant communities that exceed the boundaries of this country is obscured by their very status as immigrants. We contend that any study of immigrant integration and resettlement requires an examination of migrant experience both within and beyond Canadian borders, as well as critical scrutiny of all territorially-defined notions of migration. Critical examination of assumptions about immigration is important precisely because such assumptions define research questions, shape government policies, and generate common frames of reference.

One might argue that transnationalism, like immigration research, represents yet another white, Western attempt to theorize the experience of non-Western peoples, subjugating them further. Indeed, the disparate social status and power relations between two Anglo-North American researchers and a group of recent Burmese migrants collaborating to conduct this research are worthy of critical reflection. If, however, transnationalism and its hybrid cultural forms are contextualized as a form of local response and remaking of global and international forces, as Néstor Garcia Canclini (1995) contends, they hold out the possibility of a transformative politics. Furthermore, insofar as the methods of research are themselves open to debate and change based on the interests and priorities of the Burmese newcomers, more accountable research practices may be part and parcel of such a transformative politics.

To adopt the language of transnationality first entails a discussion of how issues of migration have primarily been framed from the perspective of the state (Ravenstein 1885). International migration has been explained, in large part, based on disparities in economic development between countries (Isbister 1996). Such interpretations tend to be overly simplistic because they assume free and rational choice on the part of individuals and do 
not account for the social and political context in which migration occurs (Helweg 1987). In Canada, government recognition of transnational ties is primarily economic in meaning, as investment opportunities and business capital are sought through the immigration of wealthy Asian business immigrants (Nash 1994; Froschauer 1998). Though these are central motivating factors for migration, scholars are becoming increasingly aware of the role social networks play in shaping migration steams (Gorter et al. 1998), and how past and present relations of colonial power, trade and foreign policy influence migration (Sassen 1996). Immigration is, then, a social, political, and transnational phenomenon that tends to build upon connections across international borders. Not only do migrants' movements occur within a larger geopolitical context and global economy, they are often an expression of such relationships. Analyses of migration should account for the conditions in the source and destination countries, but migrant movement is more than a state-to-state transfer. Often there are stops along the way, and nodes which form where access to political, social, and economic resources are concentrated.

\section{Identity}

Discussions of immigration that focus on integration, adaptation, and employment outcomes solely in the destination country often overlook transnational processes, politics, and patterns that transcend, and/or subvert, the primacy of the nationstate as the de facto unit of migrant identity (Basch et al. 1994). Transnational migration operates to transcend or subvert the limits of the nation-state. As Kearney $(1995,548)$ has argued, transnationalism is very different from globalization: "whereas global processes are largely decentered from specific national territories and take place in a global space, transnational processes are anchored in and transcend one or more nation-states." Whereas globalization renders transnational migrants and their connections across borders as incidental or largely irrelevant (except perhaps as a labor source or outcome of multinational capitalism), transnationalism views them as constitutive of distinct social, cultural, political and economic spaces which encompass, but do not adhere to, the more straightforward categories of nation, class, ethnicity, and gender.

Decentring static identity categories has been an important project for feminist scholars who theorize and politicize transnationalism from within cultural studies by employing a more explicitly postmodern approach to migration and its politics. 'Transnational feminist practices', for example, focus on "the effects of mobile capital as well as the multiple subjectivities that replace the European unitary subject" (Grewal and Kaplan 1994, 7). Processes which constitute and fragment migrant subjectivity are analyzed within the purview of the geo-politics of postmodernity. Geographically speaking, transnationalism is about identities which traverse multiple places (Nolin Hanlon \& Kobayashi 1998). Modalities which construct centres and margins, such as First and Third World, are challenged by transnational approaches that examine ways that women are constructed in subordination or positioned unequally in discourses of nationalism and/or the patriarchal state.

Such approaches to transnationalism examine the processes of identity formation, and the unequal links which constitute these maps of power. Concepts of 'immigrant' and 'refugee' for example, are defined by juridical and political apparati of national governments, premised upon the territoriality of nations, and predicated on the political borders of individual states. They are pure categories of migrant status which do not always capture the contradictions and politics of historical and geographical experience. Refugees, in the modern sense, are defined under the United Nations 1951 Convention Relating to the Status of Refugees and its 1967 Protocol. Under the Convention, "a refugee is protected from forced repatriation to the place where he or she would face persecution... based on race, religion, nationality, political opinion or membership in a particular social group" (CIC 1999). A refugee is therefore defined as one who is outside the borders of her nation-state due to violence or persecution, and displaced from what has become the centred norm of citizenship, or 'placement', within her country. An immigrant, on the other hand, is seen to replace one nationalist identification with another (Kaplan 1996); he is a newcomer, a former outsider now authorized to participate in, if not belong to, the 'host society.' The refugee is expelled from her state; the immigrant is incorporated into his. Both are territorially rooted, sometimes overlapping, conceptions of migrant status defined by the borders of the nation-state as a territorial entity. And yet neither 
term captures the ongoing economic, social, and political ties that refugee/immigrants maintain with their families, friends, and allies left behind. Analyzing conditions of displacement from a country that represents 'home' is a critical component to understanding newcomers' experience, priorities, and civic participation in a Canadian context. This is especially salient in the case of involuntary refugee movements.

The materiality and corporeality of transnationalism creates a vibrant theoretical and political surface for subjects who cross national boundaries, whether through human migration, economic ties, or political alignment. The emerging literature on transnationalism, however, tends to focus on economic and cultural analyses at the expense of political considerations, in particular, conditions of displacement. The failure of transnational discourse to adequately theorize the diversity of experiences bound up in migrant flows remains a problem. The conditions precipitating forced migration and the politics it produces represent one example. Relatively little is said about refugees, whose politically induced migration involves elements of cultural dislocation and economic costs. Political and economic crises often act as catalysts of migration and motivate people to maintain ties after they move and even to return home. Existing analyses do not address the problematic construction of 'refugee' as an expression of state-based discourse. Immigrants and refugees may more appropriately be thought of as transmigrants, individuals who maintain a number of different ethnic, national, and racial identities, who may support an opposition party or human rights movement from afar and/or return to participate in a new government (Glick Schiller et al. 1992). These transnational connections remain largely absent from most immigration research.

Differences in class, (Mitchell 1993), gender (Massey 1993), and mobility (Shami 1996; Hyndman 1997) also demand further attention. Mobility, for example, is highly gendered. Not all people have the same access or ability to move. Mobility is rooted in socioeconomic status, childcare responsibilities, and geographical location among other factors. To apply for refugee status, access to visa posts for women is often more restricted than access for men because of the burdens presented by the prevailing gender division of labour in refugee camps, on the one hand, and the loss of livelihood and income which tends to accompany displacement, on the other (Hyndman 2000). Mobility is also gendered once refugee status is granted, and governments must select which refugees will come to their countries. Boyd (1999) illustrates that Canada admits more male than female refugees and contends that women are less likely than men to meet the government's admissibility criteria. Admissibility refers to the ability to successfully settle in Canada. She notes that refugee women who make a claim from outside of Canada are not considered under the government's 'Guidelines for Gender-Related Persecution'. Location too matters: only those women who can make their way to a Canadian port of entry have access to these gender-sensitive criteria. Further accounts of transnationalism must attend to the embodied, material dimensions of movement on a human scale, in order to elucidate processes of marginalization and exclusion among particular groups.

Space

While some notable anthropologists have focused upon refugees within a context that problematizes the identities and boundaries of nations (Malkki 1995; Shami 1996), most scholars engaged in studies of transnationalism are concerned with circuits of migrant movement in relation to their economic activity, with obvious connections to social and spatial relations, and in cultural studies, to the construction of diasporic identities. Both sets of analysis are important to demonstrate the imbrication of migrant identities and the social relations which position these identities unequally in economies of 'nations unbound' (Basch et al. 1994). Sociologist Luin Goldring (1996), focusing on the patterns of return migration for Mexican workers employed in Las Animas, California, chronicles the creation and maintenance of a transnational social space across the US-Mexican border. Goldring defines 'transnational communities' as dense social fields consisting of people, money, goods, and information that are constructed and maintained by migrants over time, across space, and through circuits which repeatedly cross borders. What these movements suggest is that borders themselves are less political containers and demarcated sites of absolute state control, but zones of frequent traffic where borders are crossed and the space reconstructed through the constant movement of people, information and capital. 
In relation to this latter category - capital - borders have become most porous (Basch et al. 1994; Sassen 1996). Geographers have made major contributions to this field of investigation, but as Katharyne Mitchell argues this discourse of economic globalization has itself become homogenous and needs to 'bring geography back' into its understanding of the role of the state in relation to migrants and accompanying flows of capital. This, she suggests, can be developed by theorizing border zones; "as highly contested and dynamic areas of ideological cultural and physical turmoil... spaces of possibility as well as spaces of control" (Mitchell 1997, 106). Borders have political and material effects, but so too do the relations of exchange, solidarity, and support that cross them.

Transnationalism is differentiated from more conventional immigration studies by its insistent deconstruction of the nation-state as a primary category of analysis. References to this process include "relations stretched out over space" (Massey 1993, 66), the articulation of the local and the global (Hall 1991), and the global production of locality and translocalities (Appadurai 1996). Arjun Appadurai's (1996) work is a key example of how transnationalism complicates state-centric accounts of migration. Global relations and events become manifest locally, through the "globalized production of locality" (Appadurai 1996, 42). Increasing cross-border migration coupled with developments in communication technology have generated globally dispersed groups who create their identities and communities outside of the territory of the nation-state along the lines of an 'imagined community', whether regional, national or religious (Anderson 1983).

These new cultural clusters emerge as 'translocalities', and are often located in border zones or within major urban centres receiving large proportions of immigrants. Accordingly, global cities are often ambiguously related to the power and identity of the nation-state (Appadurai 1996; Sassen 1996). They constitute spaces for transnational identities and homes to emerge. Within the global city, immigrant groups instantaneously share information between home and host localities, shaping the quotidian lives of not only diasporic groups, but their surrounding neighbours, communities and governments. Such migrants become important actors in transferring information, and maintaining linkages among nations and across the borders of nation-states. The concentration of transnational migrants in global cities results in the jostling of a plethora of cultural forms in a highly circumscribed space, resulting in new cultural expressions, fusions, and antagonisms. Global communications technologies play an important role in maintaining established identities and creating new ones through film distribution, home videos, letters, phone calls, and religious and nationalist materials. Gillespie (1995), for example, presents a rich empirical examination of how Indian film and media contribute to the formation and maintenance of identity for Punjabi teenagers in London. Her work examines the ways in which transnational connections shape the ways migrant communities establish and maintain their cultural identities, despite the dislocations accompanying immigration. The potential of these human networks to operate across space and at various scales complicates the very concept of localities, be that the home, the city, or the nation (Rouse 1991; Appadurai 1996).

These altered discourses of space usher in completely different understandings of what immigration means for the individual and the host and home states. Appadurai (1996) mentions Vancouver as one of these new translocalities. It is a place where immigrants are not simply newcomers who assimilate and integrate into Canadian society, but one in which individual and group identities and livelihoods make and remake the places in which they come to live. They are constituted across a field of discrete locations, from Hong Kong to Vancouver (Mitchell 1993), Oaxaca to Poughkeepsie, New York (Mountz and Wright 1996), Vancouver to the Punjab, India (Singh Bains and Johnston 1995), or Thai refugee camps to Vancouver, as our study found. Though empirical studies are still limited in number, especially in Canada, the provocative departure points of transnationalism and their socio-spatial articulations represent a rich and promising arena for immigration research.

\section{The Burmese Democratic Organization in Vancouver}

Our project began in 1996 with a series of meetings in Vancouver between one of the authors and one of the central figures in the Burmese Democratic Organization. These meetings had several purpos- 
es: to discuss and exchange information about the current situation in Burma and in particular about conditions in the Thai camps hosting Burmese refugees; to develop further rapport (at the outset of the project both persons had known each other as acquaintances for one year); and to discern whether there was any common ground to proceed with a research project. The meetings were broadened over time to include a larger complement of BDO members and to involve the second author.

The approach was transnational in its conception. The project included a preliminary research trip to one of the refugee camps located in Mae Hong Son province, Thailand, along the border with Burma. Meetings were held with student lead: ers of the All Burma Student Democratic Front (ABSDF) in the camp and in the nearby town of Mae Hong Son where international nongovernmental organizations were also available for consultation. Access to the refugee camp was arranged for one of the authors by BDO members in Vancouver, highlighting the very transnational nature of communication and social organization among displaced Burmese in Thailand and Canada. The morale among refugee leaders in the camp was low, in large part because they had lost land in Burma formerly held by Burmese rebel groups. The transition from defenders of their territory at the Burma border to idle refugees and unwanted guests in Thai camps was not an easy one. The vulnerable location of the camps, just a few kilometres from the Thai-Burma border, made refugees the target of mortar attacks by Burmese soldiers on Thai soil (Ghosh 1996).

Camps in Mae Hong Son province have hosted refugees from Burma for almost a decade. Refugee numbers have grown since Burma's military launched numerous offensives against ethnic minorities at Burma's border over the past four years. For those who have come to Canada, the camps have been a transit point for most en route. Why are Burmese refugees coming to Canada and other resettlement countries in the first place? A background sketch of conditions in Burma which have forced some people to leave provides context.

\section{Human displacement from Burma to Vancouver}

Political instability and ethnic strife have affected Burma since independence from Britain in 1948. Since 1988, however, the actions of the State Law and Order Restoration Council (SLORC), recently renamed the State Peace and Development Council (SPDC), which governs Burma by military decree, have caused widespread human displacement. On August 8,1988 a popular uprising against the military government by civilians on the streets of Rangoon was met with redoubled repression and violence. Thousands of unarmed students, civil servants, and other citizens were shot by military forces and killed. Aung San Suu Kyi, daughter of revolutionary independence leader Aung San, spoke out against the government and was subsequently placed under house arrest in 1989. In 1990, free elections were held, and the National League of Democracy (NLD), an opposition party to which Aung San Suu Kyi belonged won the election with well over 80 percent of the seats. SLORC did not concede defeat and refused to allow the NLD to take power. In the past couple of years, numerous reports by UN, human rights, and refugee organizations have documented SLORC's on-going violation of human rights in Burma (Human Rights Watch 1998). These include forced labour, forced relocation particularly of ethnic minorities away from urban centres, and torture, among other charges (Herald Tribune 1999).

Many Burmese citizens who opposed and/or feared the practices of their governments, including a large group of students, fled to the Burma side of the border with Thailand in the late 1980s to areas controlled by armed ethnic minorities whose opposition to their marginalization by government was longstanding. As the strength of the SLORC military increased, however, minority ethnic groups, which had claimed much of the border area since independence in 1948, and other displaced groups, including students, were forced to give up their arms and seek safety in refugee camps on the Thai side of the border. Today these camps are growing, with 17,000 new refugees seeking safety in Thailand during 1997, this brings the total number of Burmese refugees to 130,000 . The US Committee for Refugees also estimates that another 350,000 people live in refugee-like circumstances, but without official status (World Refugee Survey 1998).

Through coerced activities based on foreign investment in Burma and the widespread use of porters by the military, the government has exacerbated slave labour and the dislocation of minority ethnic groups within Burma. Land formerly controlled by these ethnic groups, especially along the 
border with Thailand, now falls under control of the Burmese military so that strategic areas necessary for the construction of a major natural gas pipeline project between Thailand and Burma are secure. The pipeline is financed by UNOCAL and TOTAL, US and French companies, underscoring Sassen's point that economic and political alliances have everything to do with migration.

In addition to the distinction between students and ethnic minorities among Burmese refugees, there are, in effect, two kinds of refugees in Thailand: those designated 'persons of concern' by the United Nations High Commissioner for Refugees (UNHCR) in Bangkok, currently living in a safe camp in Ratchaburi province; and those living along the Thai-Burma border who are not officially recognized but do receive assistance from a number of international non-governmental organizations (NGOs). Refugees at the border must travel to UNHCR in Bangkok to seek status as persons of concern, despite Thai Government permission in 1998 for UNHCR to establish a presence at the border (The Nation 1998). Persons of concern are not refugees per se because such a designation can and has troubled bilateral political relations between governments in Bangkok and Rangoon, Burma's capital (Human Rights Watch 1998). In conjunction with several multinational companies, the governments of Thailand and Burma have cooperated on a number of cross-border investment and infrastructure projects. Given little political pressure on SLORC from either Thailand or the Association of Southeast Asian Nations (ASEAN), resettlement out of Thailand for those displaced takes on more urgency. At this time, refugees who have been living along the Thai-Burma border for more than a decade are losing hope that they will defeat the military government and return home. Many have remained at the border based on eventual return to Burma. As this possibility fades, these unrecognized refugees fuel an increasing demand for resettlement to Canada and elsewhere because there are virtually no other options.

Consular officials from the few countries with immigration programs interview and recruit small numbers of prospective immigrants, based on screenings and recommendations from UNHCR. From here, fortunate few are provided with visas and make their way to Canada. We seek to represent, albeit partially, selected aspects of Burmese refugee experience based on interviews conducted in the Greater Vancouver Area.

\section{Burmese transnationality: the Canadian context}

To our knowledge, this is the first university-sponsored research project to examine the settlement experiences of Burmese immigrants in Canada. In this final section, we outline the methodology employed and present selected findings related to transnational ties, moving then to an analysis and discussion of the relationship between transnationalism and community-based research approaches. In cooperation with the Burmese Democratic Organization, fifty interviews were conducted by interviewers selected from Burmese identified by BDO during the summer of 1997. A combination of closed and open-ended questions were posed, including a wide range of questions related to tenure in Thai camps, education and occupational status in Burma and in Canada, language abilities, family and household composition, household location, employment status, on-going contact with Burmese family and friends in other places, as well as current concerns and obstacles faced in Vancouver. Twenty-nine men and twentyone women were interviewed. This gender ratio roughly approximates the pattern of Burmese arrivals to $B C$ in which men outnumber women. Of fifty respondents, all had spent between eighteen months and nine years as displaced persons in Thailand.

The findings most pertinent to this discussion are the transnational connections that the vast majority of those interviewed maintain with Burmese outside of Canada. While the interview findings lack ethnographic depth and elaboration, they provide a preliminary picture. Evidence from the fifty interviews suggests that transnational connections are numerous and diverse and many people have parents, siblings, and children back in Burma. One person reported close friends in Thailand, Indonesia, Singapore, and Burma, a sister in the US, an uncle in Singapore, cousins in England, and relatives in Australia. Among friends in Thailand, many are in the so-called 'safe camp' where refugees are held in Ratchaburi province, west of Bangkok. Transnational communication and ties are critically important.

Telephone calls and mail are the most common forms of this communication, though mail to Burma is problematic because much of it is checked by the authorities and subsequently goes 


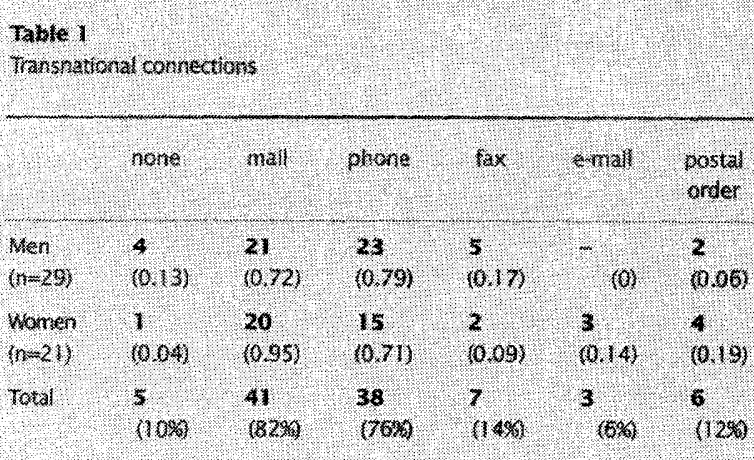

Auwal occurences shown in bold, fgures bekow ake hecuencies and percent of occurences in totah

missing. Many of the 50 interviewees send information, money, and other material to overseas contacts. The incidence of such contact suggests that women are more active as the messengers of news, information, and resource sharing since the use of postal orders is twice as common for women as for men (Table 1).

What is most remarkable is that more than half of the respondents to this question said that the type of contact they maintain with other Burmese is human rights-oriented. Migrants who come to Canada as Convention refugees or refugee claimants are more likely to have this kind of connection at this scale. Their departure is often involuntary, and the conditions which force their migration - as in the case of Burma - are related to human rights atrocities and violations of international law. The potential impact of these activist activities by Burmese living in Canada and the US should not be underestimated. During the summer of 1999, Burmese activists in Vancouver organized a hunger strike protesting conditions in what they termed the 'slave nation' Burma. Their visible efforts to educate and motivate the Canadian public to push for change forge concrete connections between the otherwise elusive and abstract 'global village' and the streets of Vancouver. Such human rights-based efforts cover a wide range of both formal and informal activities. In Vancouver, Burmese new year celebrations have been held for the public at which taped video messages from Burmese democracy leaders are shared. The importance of global communications technologies in maintaining connections across space are clear. Taped messages from Aung San Suu Kyi, leader of the National League of Democracy (NLD) and Nobel Peace prize winner, such as the message aired in 1995 at the Fourth World Conference on Women in Beijing, are considered subversive and important precisely because her personal mobility is restricted by the military government through house arrest and other impositions on her freedom. Similar kinds of videos, based on footage smuggled out of Burma by investigative journalists, are shown at church fundraisers on Granville Street in Vancouver. The Burmese Round Table meets monthly to discuss political developments in Burma and organize and coordinate responses. BDO caters events at churches and conferences to raise money for refugee camps and raise the profile of the plight of Burmese. All of these organizations and activities are performed in a transnational social space in which activities, money, and information regularly cross borders.

The most official form of this transnational politics is The National Coalition Government of the Union of Burma (NCGUB), a well-organized government in exile located in Washington D.C. The NCGUB is backed by funding and support from The Soros Foundation's Open Society Project, which connects a number of advocacy and grassroots groups across North America, among other funders. By strengthening civil society among groups based outside of Burma and by providing support for democratic process in general, the Soros Foundation's projects employ transnationalist assumptions in practical ways.

Such political connections complicate the conventional analysis of immigration as a one-way process and its assumption that integration and adaptation into the society of the host state will prevail over former ties. The precarious situation of internally displaced persons in Burma and refugees in Thailand leads to social and political networks of solidarity and in some cases survival. As demonstrated, evidence of such links include active fundraising and human rights organizing by Burmese in Vancouver who send money, supplies and information to friends and relatives at the Thai border and elsewhere. The potential impact of these networks, including the possibility of shaping refugees' lives back in Thailand, challenges conceptions of immigration that view the process as the termination of this historical relationship and the commencement of a new and discrete identity as immigrant.

These transnational social, economic, and politi- 
cal relations may become an increasingly important factor for the government of Burma/Myanmar, as overseas communities draw increasing attention to the oppressive practices of the government. We consider the growing voice of Burmese overseas communities against Burma's military regime, as indicative of a growing transnational force with a potentially transformative role in shaping issues of trade and political relations. In 1997, both the US and Canadian governments imposed various trade restrictions on Burma/Myanmar, based on the increasing publicity of its abysmal record of human rights violations, and the widespread evidence of the governments complicity with the heroin trade has caused international criticism. These pressures also take on a local dimension, and are increasingly covered by the Vancouver media (The Courier 18 December 1996; Vancouver Sun 26 November 1997; Globe and Mail 4 July 1998). Dr Sein Win, Burma's prime minister-in-exile, visited Vancouver and focused attention on the links between Myanmar's military government's promotion of the heroin trade and the problems of drug abuse in Vancouver's downtown east side (Vancouver Sun 1 December 1998). The irony of the connections he draws is not lost: the US State Department estimates that 60 percent of the heroin used in North America comes from Burma (Vancouver Sun 26 November 1997). Proceeds from the heroin grown in Burma are used to finance the military government in that country; the forced labour and relocation schemes of the government have forced many people to leave; and some of these people have arrived in Canada only to continue their protest. The actions of transnational migrants, in this case forced migrants in Canada, are linked to social change and potentially transformative political practices elsewhere.

\section{Community Collaboration and the Politics of Method}

If the transnational practices of Burmese refugees are linked to social and political changes beyond Canadian borders, then research of the experience of Burmese refugees now living Canadian can contribute to, ignore, or derogate from these connections and their potential. Collaborative strategies which aim to connect across differences in cultural background, nationality, and social power, rather than to document differences as static conceptions or characteristics of new immigrants - represent an important mode of conducting research with groups of newcomers. In the current research climate, relations among academics, immigrant-serving agencies, and immigrant groups are fuelled by competition for the finite resources available to study immigration processes, resettlement outcomes, and migration patterns. Disagreement about who the beneficiaries of research should be - funders, researchers, service agencies, or the incoming migrants themselves - abounds, and concerns about the unequal power relationships between university researchers and their research subjects are raised, particularly by feminists. Rather than consciously constructing viable transnational links and solidarity with newcomer groups, however, 'research subjects' are often respectfully treated as equal but different. This arguably multicultural approach implies acceptance and tolerance of newcomers, but does little to connect them to the researchers and other natives who are interested in their experience and well-being. Such an approach admits differences exist and aims to study their impact from a place ontologically outside the migrant experience; it does not connect across differences.

During our research, conducted in conjunction with BDO, we encountered a number of these issues which we seek to underscore. Throughout the academy, scholars and especially those inspired by feminist theories, have begun to evaluate critically the research process, the power relations it frames, and its effects on the construction of knowledge (Smith 1993). For researchers involved in the Metropolis Project, a federally sponsored immigration research initiative, these issues have become more significant. At the second National Metropolis Conference in Montreal in 1997, questions of community partnership, research approach, and ethics were raised by Teresa Dremetsikas of the Canadian Centre for Victims of Torture and Adrienne Chambon, of the University of Toronto (Chambon et al. 1998). Their positive experience of community research collaboration encouraged them to challenge conventional techniques of research, and instead develop an approach based on the concept of taking a "witness stance" in dealing with issues of immigration, integration, and the atrocities and trauma of torture. The researcher is privy to information and experiences not as an active interrogator, but as one 
whose presence is consented to by the person affected. This suggests that academic researchers involved in collaborative projects may reformulate their own positions and priorities. For whom is the research? How will it benefit the immigrant or refugee group? Such questions become as important as those pertaining to the method of research and the form of output. Legitimate research is not only about accuracy and precision but also about method and its implications, especially in situations where the well-being of the research subjects may be affected by the research findings. Without serious consideration of these challenges, researchers risk co-opting the subjugated knowledge of immigrants to legitimize the academic project (Haraway 1991). At best, 'community partners' risk becoming marginalized once their institutional purpose has passed or their contributions have been collated, transcribed, coded and represented. At worst, research findings may adversely affect particular immigrant/refugee communities who are found to resettle less successfully than other groups.

As co-researchers and partners with the Burmese Democratic Organization in Vancouver, we were aware of some of these constraints, challenges, and risks from the outset. Accordingly, one of our main objectives was to establish a meaningful collaboration between the university researchers and BDO. We attempted to do this in a number of ways. First, we approached one of the leaders within the Burmese Democratic Organization with whom we had a rapport and asked whether the group might be interested in cooperating on a research project, and if so, what they would like to get out of it. As a relatively new and small group in the Vancouver area, these landed immigrants viewed themselves as having a very low profile in the eyes of provincial settlement agencies and various levels of government. While members of the group had been working with church groups and the media to promote issues of social justice in Burma, there was little information available about the group itself. Recognizing this, a physician and community leader who was our contact in the Burmese Democratic Organization agreed to participate as a co-coordinator. The project would ostensibly provide a needs assessment for the group's own purposes, meeting one of the goals of the organization. BDO had plans to submit future funding proposals and felt that the proposed research could be helpful to that end.

Developing a community profile and a more public presence was an important element of the project, from the perspective of BDO. The BDO coordinator and contact noted that; "we are very new coming here and we don't have all this other information, like other bigger ethnic groups" (Evaluation interview, 30 July 1997). The project represented an opportunity to develop a profile of the group and put it on the map, so to speak. The BDO coordinator also said that this project marked the first occasion that the university had taken an interest in the group and how it had settled in the Vancouver area:

"there is a lot of hope there that this project can reflect for the community welfare; that is one of the biggest motives for trust and hope that makes the project go on. I hope also that there will also be some follow up from the government with this coming on" (Evaluation interview, 30 July 1997).

This first step enabled a collaborative research agenda to be formed. This is an important methodological point, since creating a collaborative agenda can ideally prevent any one party from controlling the process, or from feeling that its agenda is being manipulated or distorted.

The BDO coordinator volunteered to organize translation of a draft interview schedule and gather a potential pool of interviewers. Seven people who could speak Burmese were selected and recruited for a training session organized in tandem by one of the researchers and the BDO coordinator. Each interviewer was responsible for conducting approximately seven interviews. People were encouraged to interview acquaintances and friends, as the results of earlier non-academic research with Burmese newcomers were poor in the absence of established trust and rapport. We shared the modest financial resources of the project with BDO members as much as possible. Interviewers were paid for their training and for each interview and interviewees also received an honorarium. The interview schedule required translation, providing participation and income for two people. In total, ten people from BDO received some remuneration directly from the project; fifty more received an honorarium for participating in interviews. Our project, then, included a large proportion of the Burmese refugee population now living in Vancouver. Considering that refugees from 
Burma began arriving in B.C. only in the early 1990 s and that the total number of Burma-born people living in Vancouver who have arrived between 1991 and April 1996 is just 225, our project reached a large segment (more than 25\%) of this immigrant group (CIC 1996b).

Project management was a key ingredient in terms of the success of the collaboration. Each author and the BDO coordinator had distinct roles which involved organizing and executing particular responsibilities, but each also had their autonomy. No one was simply given random or mundane tasks; rather, each person could decide how to accomplish a particular set of goals outlined and agreed upon from the outset. Such attempts at autonomy and team work are important in collaborative research projects since colleagues are often situated differentially in relation to resources and knowledge. Among the project coordinators, mutual respect and genuine rapport at a management level made the desire for on-going contact and cooperation more desirable. Connections between the university and the group have been on-going despite the end of the project. Some months after the research was completed BDO catered an international conference lunch at UBC as part of an effort to raise funds for Burmese refugees living in camps near the Thai-Burma border. Proceeds were sent to a refugee camp, Mae Sarieng, in Northwest Thailand. These resources were tangibly beneficial to Burmese refugees in Vancouver and abroad; the event also raised awareness of the issues affecting those back in Burma, and consolidated the relationship formed between the university and community group, albeit in a modest way.

The shortcomings of this process were also significant. Insufficient time and resources for translation were allotted to the development of the interview questions. As university researchers, an a priori list of questions constituting the interview schedule was required to meet the ethical guidelines of research at the university before the research with BDO could begin in earnest. This admittedly created a university-driven set of questions from the outset, despite meetings between BDO and the researchers to develop questions independent of the those submitted for ethical review. While interview training was paid for all participants in the project (one author, the BDO coordinator, and all the interviewers received the same honorarium for their time), a common com- mitment to achieving the same outcome, in terms of the depth and quality of findings desired, between the interviews and all coordinators was, in hindsight, not achieved. Many of the interviews submitted had short one-word answers, despite several open-ended questions and coaching on the importance of probing interviewees where information is not immediately forthcoming. In a larger project, such obstacles could perhaps have been overcome by employing a pilot set of interviews. With more time and greater resources, one way to address these issues is to develop greater rapport with a sample of the interviewees who would be willing to participate in in-depth interviews. The invasiveness of such techniques may, however, have been unpalatable to the interviewers and/or interviewees. The level of trust between those interviewed, those interviewing, and the those managing the project was perhaps inadequate.

At the conclusion of the interview process, we sought feedback on these shortcomings in a followup evaluation held among the university and BDO coordinators for the project. A number of issues were raised and observations made. It became apparent that trust was a critical factor in the modest success of the project. In the first instance, interviewers and interviewees had assurances from their community leader coordinating part of the project. The community leader had a rapport with one of the researchers who had spent more than a year working with other Burmese immigrants. BDO members felt that the researchers had good intentions, and they respected the university affiliation as a more neutral one than that of an immigrant service organization. In a transnational and political context, the university was viewed as a more legitimate institution than, for example, a direct link to the government, based on their experiences in Burma where the government was highly mistrusted.

Yet, the interviewers spoke about the reticence of some respondents to share their thoughts and experiences. The BDO coordinator mentioned that several interviewers were frustrated by the answers they received to many of the questions. Interviewees would simply say, "everything is good, good, good." Her translation of this to us attributed such responses to etiquette and politeness among Burmese, but also suggested that people need to be probed and given leading questions in order to get detailed answers. Such techniques 
were covered with Burmese interviewers during the training session, as were issues of voluntary compliance and the comfort of the interviewee. Finding a balance is a very difficult political project, not to mention a research goal. The BDO coordinator noted that people resisted criticizing organizations which might still affect them, i.e. immigrant settlement services or $\mathrm{CIC}$, because they feared reprisals. The lack of disclosure during interviews may also be related to the earlier question of trust and negative experiences back in Burma, a point which underscores the importance of ascertaining political and cultural circumstances in one's country of origin.

\section{Conclusions}

From the outset, a significant degree of hope was pinned to the project. It was perceived as a potential tool for assisting Burmese people now living in Vancouver, both in providing more services for settlement and as a basis for further self-promotion and community development. We argue that such genuine aspirations are critical to effective community partnerships, and yet they also creates pressure for researchers to meet expectations which are not always made explicit. These issues of trust, community expectation, and visibility are not generally factors in the development of methodology for scholarly research. Our evaluation of collaboration with BDO elucidates the importance of considering such variables. Just as research concerning refugee-immigrants introduces methodological issues which cross cultures and social distance, so too does such research demand a theoretical context that incorporates experience and connections that exceed the borders of the country of destination. For these Burmese newcomers, integration and resettlement do not simply occur within the parameters and borders of the Canadian state. As the research findings show, most Burmese refugees in Canada maintain social, political, and economic ties or transnational connections to Burmese elsewhere. The idea that the nation is narrated (Bhabha 1990), that it is but one story of belonging to a sovereign state, is important, especially for refugees whose arrival in Canada is complicated by extenuating circumstances in their home countries. People whose sense of identity is defined by collective histories of nation and culture, as well as shared visceral geographies of displacement and violent loss, will not simply forget or abandon these connections upon arrival in a new country. This is highly relevant to Canada, where many distinct cultural groups live within the boundaries of a single nation-state, but their lives are constituted by more than one geographical location and more than one appellation.

What does transnationalism mean for immigration policy in general, and experiences of refugee resettlement in particular? Our study reveals as much about the people and conditions Burmese newcomers in Vancouver left behind, as about the challenges of their settlement in $\mathrm{BC}$. A segment of Burmese newcomers to $\mathrm{BC}$, those associated with $B D O$, agreed to undertake this research as a step towards building their own proposals which would seek resources for unmet needs and ongoing community development. The extent to which the research project and findings will contribute to this goal remains to be seen. As researchers, our aim is to fulfill the expectations of BDO by disseminating findings and presenting this information in ways that can have practical applications. We also heed the lessons learned from this project as a basis for contributing to more transnational ways of understanding and participating in the issues facing immigrants, refugees, and transmigrants. A transnational approach to migration research offers potential change in the salient mode of knowledge production and the relationship between migrants and the state.

In a national context, Burmese immigrants to $\mathrm{BC}$ are a small group with fewer resources and less experience over time in sorting out settlement issues, remaining relatively invisible to organizations which assist immigrants and refugees. On a more global scale, the Burmese Democratic Organization, which has expanded its work over the duration of the research project to create the Burma Roundtable in Vancouver, works across borders conducting human rights campaigns and connecting with friends and family abroad, sending money, materials, and information. The modest size of this group may affect its lack of political importance to government and settlement organizations in Canada, but on-going human rights violations in Burma, growing refugee populations in nearby Thailand, and recent Canadian sanctions on Burma promise a sizeable increase in the size of this immigrant group in Canada over the next few years. 


\section{Acknowledgments}

The authors would like to express their appreciation to all those who participated in this research project, in particular, Dr. Win and the members of the Burmese Democratic Organization. Thanks to Alison Mountz and two anonymous reviewers for their constructive comments. Finally, we would like to recognize the financial support of the Vancouver-based Centre for Research on Immigration and Integration in the Metropolis (RIIM) and of SSHRC which provided a postdoctoral fellowship for the period of this research.

\section{References}

ANDERSON, B. 1983 Imagined Communities: Reflections on the Origin and Spread of Nationalism (London: Verso)

APPADURA, A. 1996 Modernity at Large: Cultural Dimensions of Globalization (Minneapolis: University of Minnesota Press)

BASCH, L., GLICK SCHILLER, N., and SZANTON BLANC, C. 1994 Nations Unbound: Transnational Projects, Postcolonial Predicaments and Deterritorialized Nation-States (Pennsylvania: Gordon and Breach)

BHABHA, H.K. ed. 1990 Nation and Narration. (London/New York Routledge)

BoYD, M. 1999 'Gender, refugee status and permanent settlement' Gender Issues, 17, 5-25

CHAMBON, A., ABAI, M., DREMETSIKAS, T., and MCCRATH, S. 1998. 'Methodology in university-community partnerships: the link-by-link project as a case study' in Metropolis Year II: The development of a comparative research agenda. Proceedings of the Second National Conference, Montreal, Quebec November 1997, 151-169

CMIZENSHIP AND IMMICRATION CANADA (CIC), 1999 http://cicnet.ci.gc.ca/ english/refugee/ref3

_. 1996b Census Nation Series.

THE COURIER 1997 'Fleeing Burma's hidden war' January 8th, 1,4,5

FROSCHAUER, K. 1998 'East Asian Immigrant Entrepreneurs in Vancouver: Provincial Preference and Ethnic Strategy' Vancouver Centre of Excellence, Research on immigration and integration in the Metropolis, Working paper series \$98-01.

GARCiA CANCLINI, N. 1995 Hybrid Cultures (Minneapolis: University of Minnesota Press)

$\mathrm{GHOSH}_{4}$ A. 1996 'A Reporter at Large: Burma' New Yorker, August 12, pp. 38.55.

GILLESPIE, M. 1995 Television, Ethnicity and Cultural Change (London: Routledge)

GLICK SCHILLER, N., BASCH, L. and BLANC-SZANTON, C. 1992 'Transnationalism: a new analytic framework for understanding migration' Towards a Transnational Perspective on Migration: Race, Class, Ethnicity, and Nationalism Reconsidered (New York: Annals of the New York Academy of Sciences), 1-24

-. 1995 'From immigrant to transmigrant: theorizing transnational migration' Anthropology Quarterly 68, 48-63

THE GLOBE AND MAIL, 1998 'Rape of ethnic women just another strategy for Burmese army' July 4 th, D4

COLDRING, L. 1996 'Blurring borders: constructing transnational community in the process of Mexico-U.S. migration' Research in Community Psychology 6, 69:104

GORTER, C., NIJKAMP, P. and POOT, J. 1998, Eds Crossing Borders: Regional and Urban Perspectives on International Migration (Aldershot, Hants: Ashgate)

GREWAL, I. and C. KAPLAN. 1994 'Introduction: transnational feminist practices and questions of postmodernity' in Scattered Hegemonies: Postmodernity and Transnational Feminist Practices, eds l. Grewal \& C. Kaplan (Minneapolis: Minnesota University Press)
$1-33$

GUPTA, A., and FERGUSON, J. 1992 'Beyond "culture": space, identity, and the politics of difference' Cultural Anthropology 7, 6-23

HALL, s. 1991 'Old and new identities, old and new ethnicities' in Culture, Globalization and The World-System: Contemporary Conditions for the representation of identity, ed A. King (State University New York: Department of Art and Art History)

haRAWAY, D. 1991 'Situated knowledges' in Simians, Cyborgs, and Women: The Reinvention of Nature (New York: Routledge) 183-201

HELWEG, A. W. 1987 'Why leave for America? A case study approach to understanding migrant behaviour' International Migration/ Migrations internationales 25, 165-176.

HERALD TRIBUNE 1999 'Editorjal: repressive Burma' July 6

HUMAN RIGHTS WATCH 1998 'Unwanted and Unprotected: Burmese Refugees in Thailand' vol. 10, no. 6, September

HYNDMAN, J. 2000 Managing Displacement: Refugees and the Politics of Humanitarianism (Minneapolis: University of Minnesota Press).

- 1997 Border Crossings Antipode, 29, 149.176

HYNDMAN, J, and WALTON-ROBERTS, M. 1999 'Migration and Nation: Burmese Refugees in Vancouver' Working paper \#99-07 for the Research on Immigration and integration in the Metropolis (RIIM) series, February (see below)

-. 1999 'Migration and Nation: Burmese Refugees in Vancouver' online: http://www.riim.metropolis.net/research-policy/researchpolicy2/Papers_e.html

ISBISTER, J. 1996 The Immigration Debate (West Hartford, Connecticut: Kumarlan Press Inc.)

KAPLAN, c. 1996 Questions of Travel: Postmodern Discourses of Displacement (Durham: Duke University Press).

KEARNEY, M. 1995 'The local and the global: the anthropology of globalization and transnationalism' Annual Review of Anthropology 24 547-65

MALKKI, L. 1995 "Refugees and exile: from "refugee studies" to the national order of things' Annual Review of Anthropology 24, 495523

MASSEY, D. 1993 'Power-geometry and a progressive sense of place' in Mapping the Future: Local Cultures, Global Change eds. J. Bird, B. Curtis, T. Putnam, G. Robertson, \& L. Tickner (New York: Routledge), 59-69

MrTCHEL, K. 1993 'Multiculturalism, or the united colors of capitalism?' Antipode 25, 263-294

- 1997 'Transnational discourse: bringing geography back in' Antipode 29, 101-114

MOUNTZ, A. and WRIGH, R., 1996 'Daily life in the transnational migrant community of San Agustin, Oaxaca and Poughkeepsie, New York Diaspora 5, 403-428

NASH, A. 1994 'Some recent developments in Canadian immigration policy' The Canadian Geographer 38, 258-261

THE NATION 1998 'UNHCR begins registration of refugees in Thai border camps', Bangkok, Oct 22

NOLIN HANLON, C. and KOBAYASHI. A. 1998 'Rewriting Canada: transnationalism as a challenge to Canadian public policy' a paper presented at the Canadian Association of Geographers Annual Meeting. Ottawa, June.

RAVENSTEL, E.C. 1885 'The laws of migration' Journal of the statistical Society 48, 167-227

ROUSE, R. 1991 'Mexican migration and the social spaces of postmodernity' Diaspora 2, 8-23

SASSEN, 5. 1996 Losing Control: Sovereignty in an Age of Globalization. (New York: Columbia University Press)

SHAMI, s. 1996 'Transnationalism and refugee studies: rethinking forced migration and identity in the Middle East' Journal of Refugee Studies 9 3-26 
SINGH BAINS, T. and JOHNSON, H. 1995 The Four Quarters of the Night: the Life-Journey of an Emigrant Sikh (McGill: Queens University Press) SMITH, D.E. 1993 Texts, Facts, and Femininity: Exploring the Relations of Ruling (New York/London: Rutledge)

U.s. COMMITTEE FOR REFUGEeS 1999 USCR homepage, October 2. http://www,refugees.org/world/statistics/wrs99_table4.htm

- 1998 World Refugee Survey, 1998 (Washington DC: Immigration and Refugee Service of America)

VANCOUVER SUN 1997 'Deadly heroin is big business for Burma.' November 26th, Al

- 1998. 'Burma's prime minister-in-exile seeks help here to gain power.' December 1, B3 